\title{
Human Papillomavirus Epitope Mimicry and Autoimmunity: The Molecular Truth of Peptide Sharing
}

\author{
Darja Kanduc $^{\text {a }}$ Yehuda Shoenfeld $^{\text {b, c }}$ \\ ${ }^{a}$ Department of Biosciences, Biotechnologies, and Biopharmaceutics, University of Bari, Bari, Italy; ${ }^{b}$ Zabludowicz \\ Center for Autoimmune Diseases, Sheba Medical Center, Affiliated to Tel-Aviv, University School of Medicine, \\ Ramat Gan, Israel; ' I.M. Sechenov First Moscow State Medical University of the Ministry of Health of the Russian, \\ Federation, Sechenov University, Moscow, Russia
}

\section{Keywords \\ Human papillomavirus L1 epitopes · Peptide sharing · Cross-reactivity - Molecular mimicry - Autoimmunity . Negative selection}

\begin{abstract}
Objective: To define the cross-reactivity potential and the consequent autoimmunity intrinsic to viral versus human peptide sharing. Methods: Using human papillomavirus (HPV) infection/active immunization as a research model, the experimentally validated HPV L1 epitopes catalogued at the Immune Epitope DataBase were analyzed for peptide sharing with the human proteome. Results: The final data show that the totality of the immunoreactive HPV L1 epitopes is mostly composed by peptides present in human proteins. Conclusions: Immunologically, the high extent of peptide sharing between the HPV L1 epitopes and human proteins invites to revise the concept of the negative selection of self-reactive lymphocytes. Pathologically, the data highlight a cross-reactive potential for a spectrum of autoimmune diseases that includes ovarian failure, systemic lupus erythematosus (SLE), breast cancer and sudden death, among others. Therapeutically, analyzing already validated
\end{abstract}

\section{KARGER}

(C) 2019 S. Karger AG, Basel

E-Mail karger@karger.com

www.karger.com/pat immunoreactive epitopes filters out the peptide sharing possibly exempt of self-reactivity, defines the effective potential for pathologic autoimmunity, and allows singling out peptide epitopes for safe immunotherapeutic protocols.

(c) 2019 S. Karger AG, Basel

\section{Introduction}

Autoimmunity derives from an immune response directed against proteins/structures normally presented within the body of the host [1]. In general, infections precede the onset of autoimmune diseases [2-9] and, since the 80 s, the sharing of sequences/structures between microbial agents and humans has been proposed as the cross-reactive molecular basis for infection-induced autoimmune diseases $[10,11]$.

During the last two decades, the advent of proteomics allowed comparative biochemical analyses of microbial and human proteomes and highlighted data never reported before, namely the high quantitative dimensions of the peptide commonality among all organisms. Indeed, starting from 2000 [12], numerous studies [13-18] have documented that microbial proteomes have an incredibly high 
number of peptide overlaps with the human proteome. The massive and widespread distribution of microbial sequences throughout the human proteome shakes up the immunological concept of a "human self" distinct and separated from "the others," be they viruses, bacteria, protozoa, plants, and others. Just examining only 30 viral proteomes, biochemical sequence analyses and mathematical calculations highlight a viral-versus-human peptide overlap amounting to 2,907,096 total pentapeptides [13]. Such a peptide commonality nullifies the boundary between the human self and the nonself, that is to say the core issue in immunology and immunotherapy $[19,20]$, since pentapeptides are minimal sufficient immunological determinants [21-25].

Hence, the awesome dimensions of the microbial versus human peptide overlap raise basic immunotherapeutic concerns. Indeed, how to distinguish, within the massive common sequence platform, the peptide sequences that can be involved in self-reactivity and lead to autoimmune diseases? How to single out peptide sequences that might be useful for immunotherapy against pathogens? As a matter of fact, the unexpectedly high extent of the peptide sharing hampers a peptide-by-peptide immunological characterization and the utilization of the peptide overlap data, thus making the goals of immunotherapy seem unattainable.

To investigate these issues, the present study (i) uses human papillomavirus (HPV) infection/active immunization as a research model since numerous epitopes from HPV variants [26] have been experimentally validated and are available at the Immune Epitope DataBase (IEDB) [27]; (ii) searches the immunoreactive HPV epitopes for peptide matches with the human proteome; (iii) describes examples of human proteins that - when hit by crossreactions generated by HPV infection/active immunization - may associate with diseases and autoimmune manifestations; and (iv) traces the confinement borders between "safe" and "unsafe" epitopes, namely, identifies HPV sequences that, by being absent in the human proteome, can be safely used for anti-HPV immunotherapy.

\section{Methods}

The immunopositive HPV L1 linear epitopes (186 sequences) were retrieved from IEDB (www.iedb.org) [27] and derived from 15 HPV types (1a, 2, 3, 4, 6b, 6, 11, 16, 18, 29, 31, 33, 44, 52, and 58). Each HPV L1 epitope was dissected into pentapeptides, that is minimal immune determinants [21-25], offset each other by one amino acid (aa). The resulting 980 pentapeptides were analyzed for occurrences in the human proteome using Pir Peptide Match program (https://research.bioinformatics.udel.edu/peptidematch/in- dex.jsp) [28]. Human proteins that shared peptide sequences with the HPV L1 epitopes were recorded and analyzed for functions and associated pathologies using UniProt database (www.uniprot.org) [29] plus PubMed and OMIM resources.

\section{Results and Discussion}

\section{Description of the Peptide Sharing between HPV L1}

Epitopes and Human Proteins

Only 95 out of the 980 pentapeptides derived from the 186 HPV L1 epitopes are uniquely present in the viral proteins and absent in the human proteome (Table 1). Aiming at visualizing the complexity and extent of the viral versus human peptide overlap, Table 1 reports shared pentapeptides with initial aa in capital format and HPV-specific pentapeptides with initial aa in small format. For example, the epitope YLKGNNGRET (IEDB ID: 74736) consists of 6 overlapped minimal immune determinants: YLKGN, LKGNN, KGNNG, GNNGR, NNGRE, and NGRET. All but one of the 6 immune determinants are shared with human proteins and are visualized with the initial aa capital marked. The pentapeptide unique to HPV (NNGRE) is given with the initial aa $\mathrm{N}$ in lowercase letters.

The 95 pentapeptides that are uniquely present in the HPV epitopes are listed in Table 2. These 95 HPV L1 pentapeptides are distributed among $71 \mathrm{HPV}$ types (data not shown) and might have immunotherapeutic utilization for active immunizations exempt of cross-reactivity.

At a glance, Table 1 clearly documents the impressively high extent of the peptide sharing occurring between immunoreactive HPV L1 epitopes and the human proteome. In practice, all of the analyzed HPV L1 epitopes are characterized by a viral-human compositional peptide mosaicism that confirms the biochemical evolutionary connection between viruses and eukaryotes [30]. Moreover, it has also to be underscored that Table 1 describes only linear HPV L1 epitopic sequences. Actually, discontinuous nonlinear epitopes add to the cross-reactivity burden and the autoimmune potential illustrated above. For example, a search through IEDB shows that the HPV L1 epitope IEDB ID 114247 corresponds to the discontinuous hexapeptide $\mathrm{A}^{158} \mathrm{~S}^{159} \mathrm{~A}^{160} \mathrm{~A}^{163} \mathrm{~N}^{164} \mathrm{~A}^{165}$, and the HPV L1 epitope IEDB ID 114248 corresponds to the discontinuous peptide $\mathrm{L}^{286}, \mathrm{~A}^{290}, \mathrm{~A}^{292}, \mathrm{~N}^{296}, \mathrm{D}^{299}, \mathrm{~T}^{309}$, $\mathrm{N}^{311}, \mathrm{~S}^{314}, \mathrm{~N}^{316}, \mathrm{~S}^{375}, \mathrm{~T}^{376}, \mathrm{E}^{378}, \mathrm{Y}^{381}, \mathrm{~N}^{383}, \mathrm{~T}^{384}$. And finally, although we do not report on protein isoforms because of space, it has to be mentioned that isoforms, expressed in different tissues and at different times of the 
Table 1. Pentapeptide sharing between HPV L1 immunoreactive epitopes and human proteins

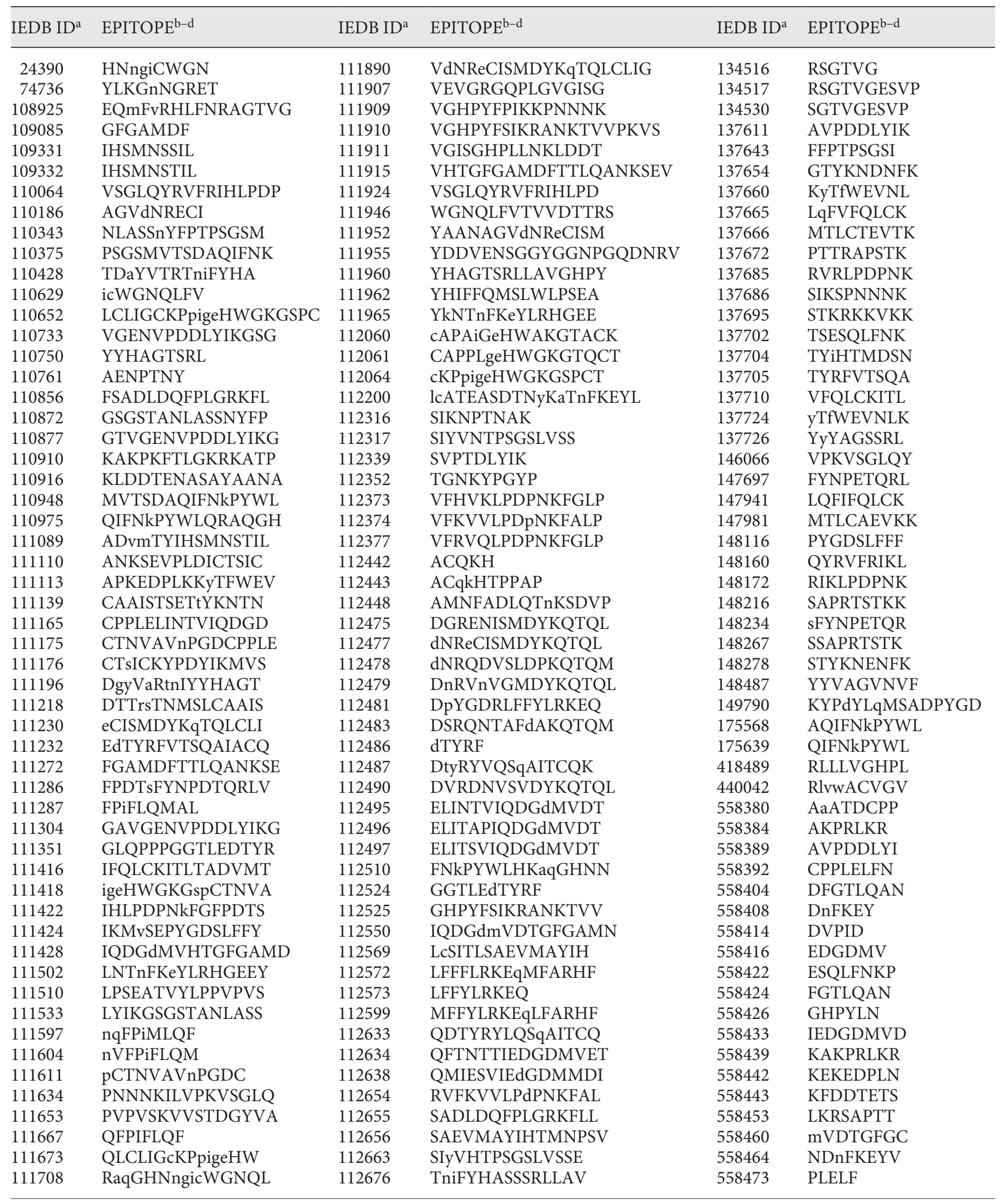

Anti-HPV Immune Response and Autoimmunity
Pathobiology 2019;86:285-295 DOI: $10.1159 / 000502889$ 
Table 1 (continued)

\begin{tabular}{llllll}
\hline IEDB ID $^{\mathrm{a}}$ & EPITOPE $^{\mathrm{b}-\mathrm{d}}$ & IEDB ID $^{\mathrm{a}}$ & EPITOPE $^{\mathrm{b}-\mathrm{d}}$ & IEDB ID $^{\mathrm{a}}$ & EPITOPE $^{\mathrm{b}-\mathrm{d}}$ \\
\hline 111725 & RHGEEYDLQFIFQLC & 112683 & TPSGSLVSSEAQLFN & 558480 & PNKFGF \\
111733 & RKATPTTSSTSTTAK & 112685 & TSifyHAGSSRLLTV & 558485 & QLFNK \\
111785 & SLFFYLRREQmFVRH & 112730 & yKEYMRHVEEFDLQF & 558491 & rYPAQPGS \\
111801 & SSILEdWNFGVPPPPTTSLV & 112759 & cSNNAITPGDC & 558523 & YLPPVP \\
111811 & STILEdWNFGLQPPPGGTLE & 113993 & VHTGFGAMDFTTLQ & 558524 & YPAQPGS \\
111826 & TfWEVNLKEKFSADL & 134343 & DLYIK & 604717 & TSDAQIFNKP \\
111846 & TqRlvwACVGVEVGR & 134509 & RHFFNRSGTV & 832586 & CISMDYKqTQL- \\
& & & & & CLIGcKPPIGE \\
\hline
\end{tabular}

${ }^{a}$ Epitopes listed according to IEDB ID number [27]. ${ }^{b}$ Epitope sequences given in 1-letter code. ${ }^{c}$ Epitope assay details and references are available at www.iedb.org [27]. ${ }^{\mathrm{d}}$ Pentapeptides shared between HPV L1 proteins and the human proteome are given with the initial aa in capital format, while pentapeptides present only in HPV L1 epitopes are given with the initial aa in lowercase format.

Table 2. Description of 95 HPV L1 epitope-derived pentapeptides that are absent in the human proteome $\mathrm{e}^{\mathrm{a}}$

\begin{tabular}{lllll}
\hline NGICW & MTYIH & KFGFP & CAPAI & DMVDT \\
GICWG & YTFWE & VSEPY & EHWAK & MVDTG \\
ICWGN & TYKNT & DMVHT & LCATE & CSITL \\
NNGRE & NPGDC & NFKEY & CATEA & QMFAR \\
MFVRH & SICKY & EYLRH & YKATN & QLFAR \\
VRHLF & GYVAR & NQFPI & ATNFK & DGDMM \\
DNREC & YVART & QFPIM & NKYPG & YVHTP \\
NYFPT & ARTNI & PIMLQ & PNKFA & FYHAG \\
AYVTR & TNIYY & IMLQF & QKHTP & YHAGS \\
NIFYH & NIYYH & NVFPI & KHTPP & YKEYM \\
IFYHA & RSTNM & AQGHN & NKSDV & CSNNA \\
CWGNQ & STNMS & QGHNN & DNRQD & FFNRS \\
CKPPI & ECISM & DWNFG & NRVNV & QFVFQ \\
PIGEH & QTQLC & FWEVN & NVGMD & IHTMD \\
IGEHW & DTYRF & QRLVW & PYGDR & YYAGS \\
GEHWG & SFYNP & LVWAC & DAKQT & DYLQM \\
EHWGK & IFLQM & VWACV & TYRYV & QMSAD \\
KPYWL & SPCTN & WACVG & YRYVQ & AATDC \\
VMTYI & PCTNV & KNTNF & QAITC & RYPAQ \\
\hline
\end{tabular}

${ }^{a}$ HPV L1 epitopes were dissected into pentapeptides and the resulting 980 pentapeptides were analyzed for occurrences in human proteins using the Pir Peptide Match program [28]. Pentapeptides absent in the human proteome were recorded.

cellular growth, introduce a further factor of complexity in the immunoreactivity scenario and might help explain the different responses of individuals to infections/active immunizations.

\section{The Pathological Implications of the Peptide Sharing}

between HPV L1 Epitopes and Human Proteins

The shared 885 HPV epitopic pentapeptides are disseminated throughout 4,938 human proteins for a total of
6,964 occurrences, including multiple/repeated occurrences. The unexpected enormous size of the peptide overlap between the HPV epitopes and human proteins can be appreciated by considering that the mathematical probability that one pentapeptide occurs in two proteins is equal to $20^{-5}$, that is, 0.0000003125 . This extremely relevant peptide sharing indicates a cross-reactivity potential capable of triggering an extremely wide and complex spectrum of autoimmune diseases that cannot be analyzed in detail because of obvious reasons of space. Then, confining the discussion to a few human proteins and reporting the shared peptides in parentheses, peptide matching analyses show the pathological scenarios that follow.

Ovarian dysgenesis, anovulation and male infertility, altered gene expression during oogenesis, premature ovarian failure, diminished ovarian reserve, accelerated primordial follicle loss, oocyte DNA damage, as well as susceptibility to breast/ovarian cancer could occur following immune attacks against DNA helicase MCM9 (LLLVG) [31]; histone-lysine N-methyltransferase 2D (GLQPP, VSSEA, HKAQG) and histone-lysine N-methyltransferase 2B (TPPAP, CQKHT, LQPPP) [32, 33]; protein KASH5 (LQPPP) [34]; histone H1oo (AGSSR, KGSGS, SSTST) [35]; protein diaphanous homolog 2 (FRIHL, GVPPP, NKFGL) [36]; breast cancer type 2 susceptibility protein (EEFDL, LKGNN, STILE, TVVDT) [37]; Bcl-2-related ovarian killer protein (VVSTD) [38]; bone morphogenetic protein 15 (KNPTN) [39]; eukaryotic translation initiation factor $4 \mathrm{E}$ transporter (HPLLN, PTTSL) [40]; and activin receptor type-2B (YLKGN) [41].

Disorders in spermatogenesis, sperm - egg fusion, or spermatid maturation and male infertility can associate with altered spermatogenesis-associated protein 16 
Table 3. Peptide sharing between HPV L1 epitopes and lupus autoantigens ${ }^{\mathrm{a}}$

\begin{tabular}{ll}
\hline Shared peptides & Lupus autoantigens \\
\hline YHASS & Complement C1q subcomponent subunit B \\
KATPT, ATPTT, TPTTS & Complement component C1q receptor \\
FTLGK & Complement C1q tumor necrosis factor-related protein 4 \\
PSGSM & Complement factor B \\
TPSGS & Complement factor H \\
RVNVG & Complement C2 \\
PLLNK, RAPST & Complement C3 \\
SRLLA & Complement C4-A \\
SRLLA & Complement C4-B \\
GVGIS, SSRLL & CO5 \\
PNKFG & CO8A \\
PPVPV & CR1L \\
TPSGS & FHR3 \\
TPSGS & FHR4 \\
STTAK, TVIQD & EEA1 \\
DTENA & ITAM \\
AQPGS & LA \\
TPSGS & LARP6 \\
LLLVG & LYAM3. P-selectin \\
SGSLV & MAGB2 \\
TSSTS & PTN22 \\
SGLQY & TNAP3 \\
VPPPP & TREX1 \\
EVPLD, LDICT & TRNK1 \\
\hline
\end{tabular}

CO5, complement C5; CO8A, complement component C8 alpha chain; CR1L, complement component receptor 1-like protein; FHR3, complement factor H-related protein 3; FHR4, complement factor H-related protein 4; EEA1, early endosome antigen 1; ITAM, integrin alpha-M; LA, lupus La protein; LARP6, La-related protein 6; MAGB2, melanoma-associated antigen B2; PTN22, tyrosine-protein phosphatase nonreceptor type 22; TNAP3, tumor necrosis factor alpha-induced protein 3; TREX1, three-prime repair exonuclease 1; TRNK1, TPR and ankyrin repeat-containing protein 1. ${ }^{a}$ HPV L1 epitopes were dissected into pentapeptides and analyzed for occurrences in the human proteome using Pir Peptide Match program [28]. Pentapeptides shared with autoantigens associated with lupus were recorded. The list of lupus autoantigens was obtained using UniProt database (www.uniprot.org) [29] plus PubMed and OMIM resources, and data from ref [56].
(AGSSR) [42]; spermatid-specific linker histone H1-like protein (FTLGK) [43]; spermatid-specific manchetterelated protein 1 (ISGHP, GHPYL) [44]; and sperm flagellar protein 2 (KKVKK, RKFLL, SESQL) [45].

Neuropsychiatric diseases including epilepsy, schizophrenia, bipolar disorder, depression, and brain cancer can derive from alterations of 1-phosphatidylinositol 4,5-bisphosphate phosphodiesterase beta-1 (KVVLP) [46]; deleted in malignant brain tumors 1 protein (SEVPL, EVPLD) [47]; neuroblastoma breakpoint family member 1 (NLKEK, SSAPR) [48]; neurofibromin (AEVMA, PLLNK, STKRK) [49]; neuronal migration protein doublecortin (LASSN) [50]; neuron navigator 3 (FKEYV, KEKED, LFNKP, SLVSS) [51]; and teneurin-2
(KVVST, LRKEQ, LWLPS, RLLAV) [52]. Actually, the potential immune impact on cell and organ functions might be even more complex because of the frequently multiple cellular functions associated with proteins. For instance, teneurin-2 is implicated in neural development and establishment of proper circuit-wiring within the nervous system, promotes the formation of enlarged growth cone in neuronal cells, induces homophilic cellcell adhesion, may function as a cellular signal transducer, and increases survival in ovarian cancer patients [53-55].

Lupus manifestations can derive from immune attacks against the lupus autoantigens listed in Table 3 [56], thus justifying recommendations and barriers to vaccination in SLE patients $[57,58]$. 


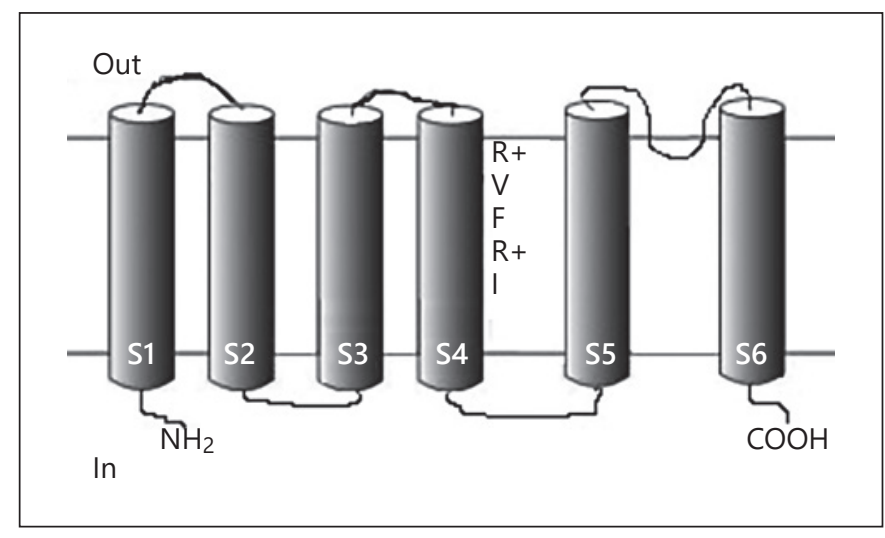

Fig. 1. Schematic structure of a voltage-gated potassium channel protein: the HPV L1 pentapeptide RVFRI is allocated in the sensor domain S4, which is involved in closing/opening the pore and the $\mathrm{K}+$ flux [66].

Altered control of the vascular dynamics, pain, fevers associated with the menstrual cycle, depression, hypotension, and dysregulation of blood pressure may follow immune attacks against $\mathrm{D}(1 \mathrm{~B})$ dopamine receptor (APPLG) [59], D(4) dopamine receptor (TPPAP) [60], 5-hydroxytryptamine receptor 1A (LPSEA) [61], 5-hydroxytryptamine receptor 7 (EVGRG) [62], beta-adrenergic receptor kinase 2 (RSGTV) [63], neurabin-2 or spinophilin (TAPIQ) [64], and sodium/glucose cotransporter 2 (LLLVG) [65].

Then, focusing on cardiac autoimmunity and sudden unexplained death, it is of remarkable importance the HPV L1 pentapeptide RVFRI shared with 11 potassium voltage-gated channel proteins (UniProt entries: KCA10, KCNA1, KCNA2, KCNA3, KCNA4, KCNA5, KCNA6, KCNA7, KCND1, KCND2, and KCND3). Voltage-gated potassium channels are proteins characterized by 6 transmembrane segments (S1-S6), 2 of which (S5-S6) form a central pore surrounded by the 4 voltage sensor domains S1-S4. Crucially, the HPV L1 pentapeptide RVFRI is allocated in the sensor domain S4 (Fig. 1), which, upon depolarization, moves outward carrying charged residues across the membrane field, thereby leading to the opening of the pore [66]. Alterations of potassium voltage-gated channel proteins have been related to Brugada syndrome and sudden unexplained death [67].

The set of potassium voltage-gated channel proteins containing the pentapeptide sensor motif RVFRI is additionally flanked by a further group of potassium-channel proteins (Table 4) that might be targeted by crossreactive anti-HPV immune responses. On the whole, im- mune attacks against these cardiac targets might lead to channelopathies that play a crucial role in sudden death and in the genesis of atrial fibrillation and cardiac arrhythmias [68], early infantile epileptic encephalopathy [69], and febrile seizure syndromes [70].

Risk of sudden unexplained death is also present when examining the high extent of peptide sharing (i.e., 30 pentapeptides, including multiple occurrences) with Titin (Table 5), a cardiac protein that, when altered, may associate with sudden death [71].

Other crucial cardiac proteins involved in the peptide sharing with HPV L1 proteins are (with shared pentapeptides in parentheses) cardiomyopathy-associated protein 5 (VKLPD) [72]; trans-2,3-enoyl-CoA reductase-like (QMSLW) that associates with arrhythmia [73], and myocyte-specific enhancer factor 2A (PPPGG, PPPPT, and PSGSL) that relates to coronary artery disease [74].

Immune Attacks against One Single HPV Epitope Can Lead to Multiple Diseases

Moreover and of very special relevance in the present context, an immune attack against one single HPV epitope can cross-react with numerous human proteins, each of which is implicated in specific pathologic manifestations (Fig. 2).

In fact, the HPV L1 epitope YDDVENSGGYGGNPGQDNRV (IEDB ID: 111955) shares the sequence

- YDDVEN with Rho guanine nucleotide exchange factor 10 that is related to slowed nerve conduction velocity and thin myelination of peripheral nerves [75];

- SGGYGG with heterogeneous nuclear ribonucleoproteins $\mathrm{A} 2 / \mathrm{B} 1$ that is a target for antinuclear autoantibodies in SLE, rheumatoid arthritis (RA), and autoimmune hepatitis (AIH) [76]; its alteration in Alzheimer's disease impairs cortical splicing and cognitive function [77] and relates to multisystem proteinopathy and amyotrophic lateral sclerosis (ALS) [78];

- SGGYGG with transcription factor Sp7 that is implicated in altered osteogenesis [79], and with keratin, type II cytoskeletal 1b or K1b expressed in skin and hair follicle, so that alteration of K1b may lead to hair loss [80];

- SGGYGG with TATA-binding protein-associated factor $2 \mathrm{~N}$, alterations of which are implicated in ALS [8183];

- SGGYGG with ATP-dependent RNA helicase A, knockdown of which increases the amount of viralderived circular RNA produced during HBV replication and the viral protein levels [84];

- GYGGNP with SWI/SNF-related matrix-associated actin-dependent regulator of chromatin subfamily D 
Fig. 2. Immune responses against HPV L1 epitope YDDVENSGGYGGNPGQDNRV can hit multiple human proteins and lead to multiple diseases.

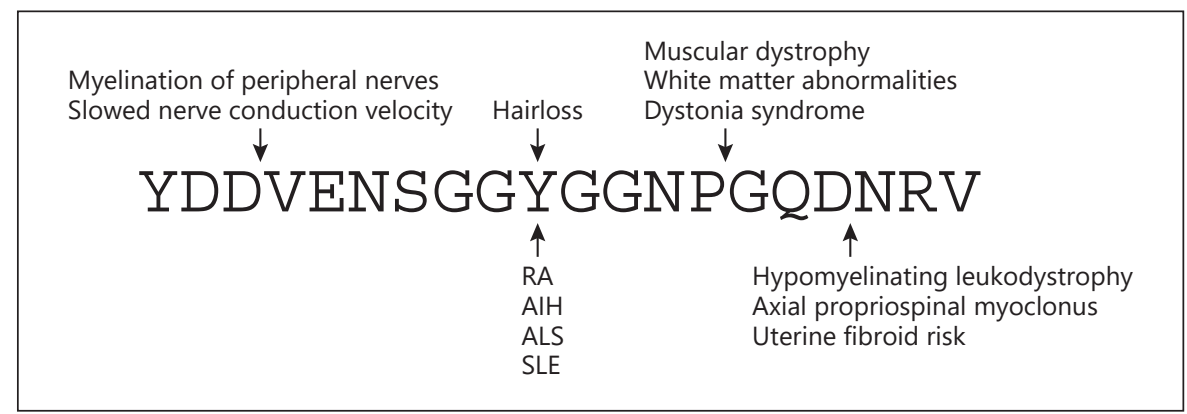

Table 4. Pentapeptide sharing between HPV L1 epitopes and potassium-channel proteins ${ }^{\mathrm{a}}$

\begin{tabular}{|c|c|}
\hline Shared peptides & Potassium-channel proteins \\
\hline TVGES & Potassium/sodium hyperpolarization-activated cyclic nucleotide-gated channel 1 \\
\hline APRTS & Potassium/sodium hyperpolarization-activated cyclic nucleotide-gated channel 2 \\
\hline KGSGS, PPPGG, RAPST & Potassium/sodium hyperpolarization-activated cyclic nucleotide-gated channel 3 \\
\hline KAKPK, AKPKF & ATP-sensitive inward rectifier potassium channel 11 \\
\hline NLKEK & ATP-sensitive inward rectifier potassium channel 15 \\
\hline KYPGY, YPGYP & Inward rectifier potassium channel 16 \\
\hline VENSG, VPTDL & Calcium-activated potassium channel subunit alpha-1 \\
\hline PAQPG & Potassium voltage-gated channel subfamily $\mathrm{C}$ member 3 \\
\hline LFVTV & Potassium voltage-gated channel subfamily G member 1 \\
\hline GSLVS, SGSTA & Potassium voltage-gated channel subfamily $\mathrm{H}$ member 4 \\
\hline TTRST & Potassium voltage-gated channel subfamily $\mathrm{H}$ member 8 \\
\hline TYRYL & G protein-activated inward rectifier potassium channel 4 \\
\hline TYRYL & G protein-activated inward rectifier potassium channel 2 \\
\hline TYRYL & G protein-activated inward rectifier potassium channel 3 \\
\hline VAGVN & Potassium channel subfamily K member 5 \\
\hline NAITP, AITPG & Potassium channel subfamily K member 12 \\
\hline VSLDP & Potassium voltage-gated channel subfamily KQT member 1 \\
\hline GKGSP, KGSPC & Potassium voltage-gated channel subfamily KQT member 2 \\
\hline ELITA, PSGSM, TPSGS, RKEQL & Potassium voltage-gated channel subfamily KQT member 3 \\
\hline ELITA & Potassium voltage-gated channel subfamily KQT member 4 \\
\hline ELITA & Potassium voltage-gated channel subfamily KQT member 5 \\
\hline KVVLP, RVNVG, SSRLL & Potassium voltage-gated channel subfamily S member 1 \\
\hline GQPLG & Potassium voltage-gated channel subfamily S member 2 \\
\hline TSESQ & Potassium channel subfamily T member 1 \\
\hline TSESQ & Potassium channel subfamily T member 2 \\
\hline VENSG & Potassium channel subfamily U member 1 \\
\hline
\end{tabular}

${ }^{a}$ HPV L1 epitopes were dissected into pentapeptides and analyzed for occurrences in the human proteome using the Pir Peptide Match program [28]. Pentapeptides shared with potassium channel proteins were recorded.

member 1 . This protein regulates hepatic fatty acid $\beta$-oxidation and its alterations can relate to metabolic syndrome [85];

- GNPGQD with collagen alpha-3(VI) chain precursor, alterations of which are related to dystonia syndrome [86], microstructural white matter abnormalities [87], and muscular dystrophy $[88,89]$;
- GQDNR with BET1-like protein that associates with uterine fibroid risk [90] and with myelin-associated glycoprotein that can contribute/lead to CharcotMarie-Tooth 1A disease [91], hypomyelinating leukodystrophy [92], and axial propriospinal myoclonus [93]. 
Table 5. Distribution of HPV L1 pentapeptides along Titin sequence ${ }^{\mathrm{a}}$

\begin{tabular}{ll}
\hline Pentapeptide & aa position \\
\hline KTVVP & $607-611$ \\
TVVPK & $608-612$ \\
VVPKV & $609-613$ \\
SLVEE & $1,799-1,803$ \\
STANL & $3,427-34,31$ \\
VENSG & $5,853-5,857$ \\
LELFN & $6,877-6,881$ \\
STILE & $7,908-7,912$ \\
KVSGL & $8,566-8,570,22,642-22,646,26,574-26,578$ \\
PPPPT & $9,940-9,944$ \\
PPPTT & $9,941-9,945$ \\
VPPPP & $10,348-10,352$ \\
TEVTK & $17,948-17,952$ \\
VVDTT & $19,432-19,436,30,277-30,281$ \\
DTTRS & $20,526-20,530$ \\
KRANK & $21,150-21,154$ \\
RANKT & $21,151-21,155$ \\
TSRLL & $21,441-21,445$ \\
SITLS & $23,184-23,188,24,266-24,270$ \\
VEETA & $25,287-25,291$ \\
SLDPK & $25,635-25,639$ \\
SEVPL & $30,559-30,563$ \\
KSDVP & $31,847-31,851$ \\
NKFGL & $32,125-32,129$ \\
VGENV & $32,630-32,634$ \\
KKYTF & $32,664-32,668$ \\
\hline
\end{tabular}

${ }^{a}$ HPV L1 epitopes were dissected into pentapeptides and analyzed for occurrences in the human proteome using the Pir Peptide Match program [28]. Pentapeptides shared with Titin were recorded and the aa positions along the Titin primary sequence (https://www.uniprot.org/uniprot/Q8WZ42) were annotated.

The Immunological Implications of the

Peptide Sharing between HPV L1 Epitopes and

Human Proteins

Immunologically, the present data dismantle the main argument against autoimmunity. Indeed, it is assumed $[19,20]$ that lymphocytes with specificity for peptides that are expressed in the human host do not proliferate and are deleted from the immunological repertoire during fetal or early life in order to avoid self-reactivity. Based on this assumption, cross-reactivity and the consequent autoimmune diseases have been and are considered as rare phenomena caused by an incomplete negative selection of self-reactive lymphocytes that produces the socalled "immunological holes" [19, 20, 94]. Accordingly, considering viruses as triggers of autoimmunity has been defined to be more a fantasy rather than a fact [95]. In conflict, we document here that the totality of the experi- mentally validated immunoreactive HPV L1 epitopes is mostly composed by peptides present in human proteins. This means that immune attacks against such HPV L1 epitopes concretize a real risk of cross-reactions with the human proteins that share the epitopic peptide sequences and are a prelude to autoimmune pathologies. Furthermore, it appears that the self-reactive lymphocytes that produced the immune responses against the $186 \mathrm{HPV}$ epitopes analyzed here have never been eliminated. In reality, it seems that the process of negative selection of selfreactive lymphocytes does not exist at all.

Rather, the widespread peptide commonality configures a non-reactivity status in almost all lymphocytes from fetal development to final differentiation, so that anti-pathogen (and cross-reactive) immune responses can occur only in the presence of stimuli such as adjuvants [96], lipopolysaccharides [97], altered glycosylation patterns [98], posttranslational modifications as citrullination [99], and chemical modification as oxidation [100] and glycation [101]. In this context, peptide commonality might also explain the silent "immunotolerated" chronic pathogen infections [102] and, as well, the vaccinology failure to induce powerful, specific, and safe immune responses against infectious agents [103]. In essence, peptide sharing with microbial proteins and, in general, with all proteomes is a condition intrinsic to human proteins and reifies immunotolerance, whereas immunogenicity resides in and identifies with peptide sequences that are extraneous to the human host (Table 2) [104].

\section{Conclusions}

This study shows a massive viral versus human peptide sharing that involves immunoreactive HPV epitopes and a highest number of human proteins that may be associated - when inhibited, deleted, mutated, modified, or improperly functioning - with pathologies and autoimmune disorders. Specifically, the present data indicate that, via cross-reactivity, the immune responses that follow HPV infections/active immunizations might lead to premature ovarian failure, oocyte DNA damage, lupus manifestations, susceptibility to breast/ovarian cancer, neuropsychiatric diseases, hypotension and dysregulation of blood pressure, cardiac disorders, and, even, sudden death. Clinically, such a vast cross-reactivity potential explains the multiple autoimmune disease syndromes that can follow infections/active immunization [105]. From the immunological point of view, the data pose fundamental questions on the negative selection issue and warrant further re- 
search. Moreover and of note, the here described analysis of experimentally validated immunoreactive epitopes not only highlights the effective cross-reactive potential capable of leading to pathologic autoimmune sequelae but also defines a scientific procedure for identifying peptide sequences to be used for safe immunotherapeutic protocols exempt of adverse events [106-108].

\section{Acknowledgments}

This research received no specific grants from any funding agency in public, commercial, or not-for-profit sectors.

\section{Statement of Ethics}

The authors have no ethical conflicts to disclose.

\section{Disclosure Statement}

D.K.: declares no conflicts. Y.S.: is a medical consultant in vaccine compensation court, USA.

\section{References}

1 Janeway CA Jr, Travers P, Walport M, Shlomchik MJ: Immunobiology: The Immune System in Health and Disease. New York: Garland Science; 2001.

2 Nielsen PR, Kragstrup TW, Deleuran BW, Benros ME. Infections as risk factor for autoimmune diseases - A nationwide study. J Autoimmun. 2016 Nov; 74:176-81.

3 Honkanen $\mathrm{H}$, Oikarinen $\mathrm{S}$, Nurminen $\mathrm{N}$, Laitinen $\mathrm{OH}$, Huhtala $\mathrm{H}$, Lehtonen $\mathrm{J}$, et al. Detection of enteroviruses in stools precedes islet autoimmunity by several months: possible evidence for slowly operating mechanisms in virus-induced autoimmunity. Diabetologia. 2017 Mar;60(3):424-31.

4 Sakkas LI, Daoussis D, Liossis SN, Bogdanos DP. The infectious basis of ACPA-positive rheumatoid arthritis. Front Microbiol. 2017 Sep;8:1853.

5 Alaedini A, Lebwohl B, Wormser GP, Green $\mathrm{PH}$, Ludvigsson JF. Borrelia infection and risk of celiac disease. BMC Med. 2017 Sep;15(1): 169.

6 Blackmore S, Hernandez J, Juda M, Ryder E, Freund GG, Johnson RW, et al. Influenza infection triggers disease in a genetic model of experimental autoimmune encephalomyelitis. Proc Natl Acad Sci USA. 2017 Jul;114 (30):E6107-16.

7 Kemppainen KM, Lynch KF, Liu E, Lönnrot M, Simell V, Briese T, et al.; TEDDY Study Group. Factors that increase risk of celiac disease autoimmunity after a gastrointestinal infection in early life. Clin Gastroenterol Hepatol. 2017 May;15(5):694-702.e5.

8 Mustonen N, Siljander H, Peet A, Tillmann V, Härkönen T, Ilonen J, et al.; DIABIMMUNE Study Group. Early childhood infections precede development of beta-cell autoimmunity and type 1 diabetes in children with HLAconferred disease risk. Pediatr Diabetes. 2018 Mar;19(2):293-9.

9 Burgueño-Montañés C, Álvarez-Coronado M, Colunga-Cueva M. Autoimmune neuroretinopathy secondary to Zika virus infection. Arch Soc Esp Oftalmol. 2018 Jul;93(7):336-41.
10 Fujinami RS, Oldstone MB, Wroblewska Z, Frankel ME, Koprowski H. Molecular mimicry in virus infection: crossreaction of measles virus phosphoprotein or of herpes simplex virus protein with human intermediate filaments. Proc Natl Acad Sci USA. 1983 Apr; 80(8):2346-50.

11 Oldstone MB. Molecular mimicry: its evolution from concept to mechanism as a cause of autoimmune diseases. Monoclon Antib Immunodiagn Immunother. 2014 Jun;33(3): 158-65.

12 Natale C, Giannini T, Lucchese A, Kanduc D. Computer-assisted analysis of molecular mimicry between human papillomavirus 16 E7 oncoprotein and human protein sequences. Immunol Cell Biol. 2000 Dec;78(6):580-5.

13 Kanduc D, Stufano A, Lucchese G, Kusalik A. Massive peptide sharing between viral and human proteomes. Peptides. 2008 Oct;29(10): 1755-66.

14 Trost B, Lucchese G, Stufano A, Bickis M, Kusalik A, Kanduc D. No human protein is exempt from bacterial motifs, not even one. Self Nonself. 2010 Oct;1(4):328-34.

15 Lucchese G, Capone G, Kanduc D. Peptide sharing between influenza A H1N1 hemagglutinin and human axon guidance proteins. Schizophr Bull. 2014 Mar;40(2):362-75.

16 Lucchese G. Understanding neuropsychiatric diseases, analyzing the peptide sharing between infectious agents and the languageassociated NMDA 2A protein. Front Psychiatry. 2016 Apr;7:60.

17 Lucchese G. From toxoplasmosis to schizophrenia via NMDA dysfunction: peptide overlap between Toxoplasma gondii and N-Methyl-d-Aspartate Receptors as a potential mechanistic link. Front Psychiatry. 2017 Mar;8:37.

18 Kanduc D, Shoenfeld Y. Inter-pathogen peptide sharing and the original antigenic sin: solving a paradox. Open Immunol J. 2018; 8(1):11-27.

19 Cohn M. Two unresolved problems facing models of the Self-Nonself discrimination. J Theor Biol. 2015 Dec;387:31-8.
20 Rose NR. Negative selection, epitope mimicry and autoimmunity. Curr Opin Immunol. 2017 Dec;49:51-5.

21 Reddehase MJ, Rothbard JB, Koszinowski UH. A pentapeptide as minimal antigenic determinant for MHC class I-restricted T lymphocytes. Nature. 1989 Feb;337(6208):651-3.

22 Zeng W, Pagnon J, Jackson DC. The C-terminal pentapeptide of LHRH is a dominant $B$ cell epitope with antigenic and biological function. Mol Immunol. 2007 Jul;44(15): 3724-31.

23 Kanduc D. Homology, similarity, and identity in peptide epitope immunodefinition. J Pept Sci. 2012 Aug;18(8):487-94.

24 Kanduc D. Pentapeptides as minimal functional units in cell biology and immunology. Curr Protein Pept Sci. 2013 Mar;14(2):111-20.

25 Hao SS, Zong MM, Zhang Z, Cai JX, Zheng $\mathrm{Y}$, Feng XL, et al. The inducing roles of the new isolated bursal hexapeptide and pentapeptide on the immune response of AIV vaccine in mice. Protein Pept Lett. 2019;26(7): 542-9.

26 Godi A, Facchetti A, Bissett SL, Cocuzza C, Miller E, Beddows S. Naturally occurring major and minor capsid protein variants of $\mathrm{Hu}$ man Papillomavirus 45 (HPV45): differential recognition by cross-neutralizing antibodies generated by HPV vaccines. J Virol. 2015 Dec; 90(6):3247-52.

27 Vita R, Mahajan S, Overton JA, Dhanda SK, Martini S, Cantrell JR, et al. The Immune Epitope Database (IEDB): 2018 update. Nucleic Acids Res. 2019 Jan;47(D1):D339-43.

28 Chen C, Li Z, Huang H, Suzek BE, Wu CH; UniProt Consortium. A fast Peptide Match service for UniProt Knowledgebase. Bioinformatics. 2013 Nov;29(21):2808-9.

29 UniProt Consortium. UniProt: a worldwide hub of protein knowledge. Nucleic Acids Res. 2019 Jan;47(D1):D506-15

30 Kanduc D. The comparative biochemistry of viruses and humans: an evolutionary path towards autoimmunity. Biol Chem. 2019 Apr; 400(5):629-38. 
31 Wood-Trageser MA, Gurbuz F, Yatsenko SA, Jeffries EP, Kotan LD, Surti U, et al. MCM9 mutations are associated with ovarian failure, short stature, and chromosomal instability. Am J Hum Genet. 2014 Dec;95(6):754-62.

32 Guo H, Zhu P, Yan L, Li R, Hu B, Lian Y, et al. The DNA methylation landscape of human early embryos. Nature. 2014 Jul;511(7511): 606-10.

33 Andreu-Vieyra CV, Chen R, Agno JE, Glaser S, Anastassiadis K, Stewart AF, et al. MLL2 is required in oocytes for bulk histone 3 lysine 4 trimethylation and transcriptional silencing. PLoS Biol. 2010 Aug;8(8):e1000453.

34 Morimoto A, Shibuya H, Zhu X, Kim J, Ishiguro K, Han M, et al. A conserved KASH domain protein associates with telomeres, SUN1, and dynactin during mammalian meiosis. J Cell Biol. 2012 Jul;198(2):165-72.

35 Mizusawa Y, Kuji N, Tanaka Y, Tanaka M, Ikeda E, Komatsu S, et al. Expression of human oocyte-specific linker histone protein and its incorporation into sperm chromatin during fertilization. Fertil Steril. 2010 Mar; 93(4):1134-41.

36 Bione S, Sala C, Manzini C, Arrigo G, Zuffardi O, Banfi S, et al. A human homologue of the Drosophila melanogaster diaphanous gene is disrupted in a patient with premature ovarian failure: evidence for conserved function in oogenesis and implications for human sterility. Am J Hum Genet. 1998 Mar;62(3): $533-41$.

37 Antoniou A, Pharoah PD, Narod S, Risch HA, Eyfjord JE, Hopper JL, et al. Average risks of breast and ovarian cancer associated with BRCA1 or BRCA2 mutations detected in case Series unselected for family history: a combined analysis of 22 studies. Am J Hum Genet. 2003 May;72(5):1117-30.

38 Jäs̈keläinen M, Nieminen A, Pökkylä RM, Kauppinen M, Liakka A, Heikinheimo M, et al. Regulation of cell death in human fetal and adult ovaries-role of Bok and Bcl-X(L). Mol Cell Endocrinol. 2010 Dec;330(1-2):17-24.

39 Di Pasquale E, Beck-Peccoz P, Persani L. Hypergonadotropic ovarian failure associated with an inherited mutation of human bone morphogenetic protein-15 (BMP15) gene. Am J Hum Genet. 2004 Jul;75(1):106-11.

40 Kasippillai T, MacArthur DG, Kirby A, Thomas B, Lambalk CB, Daly MJ, et al. Mutations in eIF4ENIF1 are associated with primary ovarian insufficiency. J Clin Endocrinol Metab. 2013 Sep;98(9):E1534-9.

41 Martins da Silva SJ, Bayne RA, Cambray N, Hartley PS, McNeilly AS, Anderson RA. Expression of activin subunits and receptors in the developing human ovary: activin A promotes germ cell survival and proliferation before primordial follicle formation. Dev Biol. 2004 Feb;266(2):334-45.

42 Dam AH, Koscinski I, Kremer JA, Moutou C, Jaeger AS, Oudakker AR, et al. Homozygous mutation in SPATA16 is associated with male infertility in human globozoospermia. Am J Hum Genet. 2007 Oct;81(4):813-20.
43 Yan W, Ma L, Burns KH, Matzuk MM. HILS1 is a spermatid-specific linker histone H1-like protein implicated in chromatin remodeling during mammalian spermiogenesis. Proc Natl Acad Sci USA. 2003 Sep;100(18):1054651.

44 Matsuoka Y, Miyagawa Y, Tokuhiro K, Kitamura K, Iguchi N, Maekawa M, et al. Isolation and characterization of the spermatid-specific Smrp1 gene encoding a novel manchette protein. Mol Reprod Dev. 2008 Jun;75(6): $967-75$.

45 Lehti MS, Henriksson H, Rummukainen P, Wang F, Uusitalo-Kylmälä L, Kiviranta R, et al. Cilia-related protein SPEF2 regulates osteoblast differentiation. Sci Rep. 2018 Jan; $8(1): 859$.

46 Yang YR, Kang DS, Lee C, Seok H, Follo MY, Cocco L, et al. Primary phospholipase C and brain disorders. Adv Biol Regul. 2016 May;61: $80-5$.

47 Pang JC, Dong Z, Zhang R, Liu Y, Zhou LF, Chan BW, et al. Mutation analysis of DMBT1 in glioblastoma, medulloblastoma and oligodendroglial tumors. Int J Cancer. 2003 May; 105(1):76-81.

48 Andries V, Vandepoele K, Staes K, Berx G, Bogaert P, Van Isterdael G, et al. NBPF1, a tumor suppressor candidate in neuroblastoma, exerts growth inhibitory effects by inducing a G1 cell cycle arrest. BMC Cancer. 2015 May;15(1):391.

49 Kehrer-Sawatzki H, Cooper DN. Mosaicism in sporadic neurofibromatosis type 1: variations on a theme common to other hereditary cancer syndromes? J Med Genet. 2008 Oct; 45(10):622-31.

50 Kim YO, Nam TS, Park C, Kim SK, Yoon W, Choi SY, et al. Familial pachygyria in both genders related to a DCX mutation. Brain Dev. 2016 Jun;38(6):585-9.

51 Maliniemi P, Carlsson E, Kaukola A, Ovaska K, Niiranen K, Saksela O, et al. NAV3 copy number changes and target genes in basal and squamous cell cancers. Exp Dermatol. 2011 Nov;20(11):926-31.

52 Silva JP, Lelianova VG, Ermolyuk YS, Vysokov N, Hitchen PG, Berninghausen O, et al. Latrophilin 1 and its endogenous ligand Lasso/teneurin-2 form a high-affinity transsynaptic receptor pair with signaling capabilities. Proc Natl Acad Sci USA. 2011 Jul;108(29): 12113-8.

53 Li J, Shalev-Benami M, Sando R, Jiang X, Kibrom A, Wang J, et al. Structural basis for teneurin function in circuit-wiring: a toxin motif at the synapse. Cell. 2018 Apr;173(3): 735-748.e15.

54 Ferralli J, Tucker RP, Chiquet-Ehrismann R. The teneurin C-terminal domain possesses nuclease activity and is apoptogenic. Biol Open. 2018 Mar;7(3):bio031765.

55 Graumann R, Di Capua GA, Oyarzún JE, Vásquez MA, Liao C, Brañes JA, et al. Expression of teneurins is associated with tumor differentiation and patient survival in ovarian cancer. PLoS One. 2017 May;12(5):e0177244.
56 Tsokos GC, Gordon C, Smolen JS, editors. Systemic Lupus Erythematosus: a Companion to Rheumatology. Philadelphia: Mosby Elsevier; 2007.

57 Wang B, Shao X, Wang D, Xu D, Zhang JA. Vaccinations and risk of systemic lupus erythematosus and rheumatoid arthritis: A systematic review and meta-analysis. Autoimmun Rev. 2017 Jul;16(7):756-65.

58 Garg M, Mufti N, Palmore TN, Hasni SA. Recommendations and barriers to vaccination in systemic lupus erythematosus. Autoimmun Rev. 2018 Oct;17(10):990-1001.

59 Tayebati SK, Lokhandwala MF, Amenta F. Dopamine and vascular dynamics control: present status and future perspectives. Curr Neurovasc Res. 2011 Aug;8(3):246-57.

60 Martikainen IK, Hagelberg N, Jääskeläinen SK, Hietala J, Pertovaara A. Dopaminergic and serotonergic mechanisms in the modulation of pain: in vivo studies in human brain. Eur J Pharmacol. 2018 Sep;834:337-45.

61 Jiang YC, Wu HM, Cheng KH, Sunny Sun H. Menstrual cycle-dependent febrile episode mediated by sequence-specific repression of poly(ADP-ribose) polymerase- 1 on the transcription of the human serotonin receptor $1 \mathrm{~A}$ gene. Hum Mutat. 2012 Jan;33(1):209-17.

62 Stam NJ, Roesink C, Dijcks F, Garritsen A, van Herpen A, Olijve W. Human serotonin 5-HT7 receptor: cloning and pharmacological characterisation of two receptor variants. FEBS Lett. 1997 Aug;413(3):489-94.

63 Oliver E, Rovira E, Montó F, Valldecabres C, Julve R, Muedra V, et al. Beta-adrenoceptor and GRK3 expression in human lymphocytes is related to blood pressure and urinary albumin excretion. J Hypertens. 2010 Jun;28(6):1281-9.

64 da Costa Goncalves AC, Fontes MA, Klussmann E, Qadri F, Janke J, Gollasch M, et al. Spinophilin regulates central angiotensin II-mediated effect on blood pressure. J Mol Med (Berl). 2011 Dec;89(12):1219-29.

65 Sternlicht H, Bakris GL. Blood pressure lowering and sodium-glucose co-transporter 2 inhibitors (SGLT2is): more than osmotic diuresis. Curr Hypertens Rep. 2019 Feb;21(2):12.

66 Kalstrup T, Blunck R. S4-S5 linker movement during activation and inactivation in voltagegated K+ channels. Proc Natl Acad Sci USA. 2018 Jul;115(29):E6751-9.

67 Giudicessi JR, Ye D, Kritzberger CJ, Nesterenko VV, Tester DJ, Antzelevitch C, et al. Novel mutations in the KCND3-encoded Kv4.3 K+ channel associated with autopsy-negative sudden unexplained death. Hum Mutat. 2012 Jun;33(6):989-97.

68 Lazzerini PE, Capecchi PL, Laghi-Pasini F, Boutjdir M. Autoimmune channelopathies as a novel mechanism in cardiac arrhythmias. Nat Rev Cardiol. 2017 Sep;14(9):521-35.

69 Nava C, Dalle C, Rastetter A, Striano P, de Kovel CG, Nabbout R, et al.; EuroEPINOMICS RES Consortium. De novo mutations in HCN1 cause early infantile epileptic encephalopathy. Nat Genet. 2014 Jun;46(6):640-5. 
70 Dibbens LM, Reid CA, Hodgson B, Thomas EA, Phillips AM, Gazina E, et al. Augmented currents of an $\mathrm{HCN} 2$ variant in patients with febrile seizure syndromes. Ann Neurol. 2010 Apr;67(4):542-6.

71 Campuzano O, Sanchez-Molero O, Mademont-Soler I, Riuró H, Allegue C, Coll M, et al. Rare Titin (TTN) variants in diseases associated with sudden cardiac death. Int J Mol Sci. 2015 Oct; 16(10):25773-87.

72 Nakagami H, Kikuchi Y, Katsuya T, Morishita R, Akasaka H, Saitoh S, et al. Gene polymorphism of myospryn (cardiomyopathy-associated 5) is associated with left ventricular wall thickness in patients with hypertension. Hypertens Res. 2007 Dec;30(12):1239-46.

73 Devalla HD, Gélinas R, Aburawi EH, Beqqali A, Goyette P, Freund C, et al. TECRL, a new life-threatening inherited arrhythmia gene associated with overlapping clinical features of both LQTS and CPVT. EMBO Mol Med. 2016 Dec;8(12):1390-408.

74 Huang XC, Wang W. Association of MEF2A gene 3 'UTR mutations with coronary artery disease. Genet Mol Res. 2015 Sep; 14(3): 11073-8.

75 Verhoeven K, De Jonghe P, Van de Putte T, Nelis E, Zwijsen A, Verpoorten $\mathrm{N}$, et al. Slowed conduction and thin myelination of peripheral nerves associated with mutant rho Guanine-nucleotide exchange factor 10. Am J Hum Genet. 2003 Oct;73(4):926-32.

76 Beleoken E, Leh H, Arnoux A, Ducot B, Nogues C, De Martin E, et al. SPRi-based strategy to identify specific biomarkers in systemic lupus erythematosus, rheumatoid arthritis and autoimmune hepatitis. PLoS One. 2013 Dec;8(12):e84600.

77 Berson A, Barbash S, Shaltiel G, Goll Y, Hanin G, Greenberg DS, et al. Cholinergic-associated loss of hnRNP-A/B in Alzheimer's disease impairs cortical splicing and cognitive function in mice. EMBO Mol Med. 2012 Aug;4(8) $730-42$.

78 Kim HJ, Kim NC, Wang YD, Scarborough EA, Moore J, Diaz Z, et al. Mutations in prionlike domains in hnRNPA2B1 and hnRNPA1 cause multisystem proteinopathy and ALS Nature. 2013 Mar;495(7442):467-73.

79 Baek WY, de Crombrugghe B, Kim JE. Postnatally induced inactivation of Osterix in osteoblasts results in the reduction of bone formation and maintenance. Bone. $2010 \mathrm{Apr}$ 46(4):920-8.

80 Rogers MA, Edler L, Winter H, Langbein L, Beckmann I, Schweizer J. Characterization of new members of the human type II keratin gene family and a general evaluation of the keratin gene domain on chromosome 12q13.13. J Invest Dermatol. 2005 Mar; 124 (3):536-44.

81 Ticozzi N, Vance C, Leclerc AL, Keagle P, Glass JD, McKenna-Yasek D, et al. Mutational analysis reveals the FUS homolog TAF15 as a candidate gene for familial amyotrophic lateral sclerosis. Am J Med Genet B Neuropsychiatr Genet. 2011 Apr;156B(3):285-90.
82 Kim Y, Kim HJ, Cha SJ, Choi HJ, Kim H, Lee $\mathrm{S}$, et al. Genetic activation of parkin rescues TAF15-induced neurotoxicity in a Drosophila model of amyotrophic lateral sclerosis. Neurobiol Aging. 2019 Jan;73:68-73.

83 Kapeli K, Pratt GA, Vu AQ, Hutt KR, Martinez FJ, Sundararaman B, et al. Distinct and shared functions of ALS-associated proteins TDP-43, FUS and TAF15 revealed by multisystem analyses. Nat Commun. 2016 Jul;7(1): 12143.

84 Sekiba K, Otsuka M, Ohno M, Kishikawa T, Yamagami M, Suzuki T, et al. DHX9 regulates production of hepatitis B virus-derived circular RNA and viral protein levels. Oncotarget. 2018 Apr;9(30):20953-64

85 Wang RR, Pan R, Zhang W, Fu J, Lin JD, Meng ZX. The SWI/SNF chromatin-remodeling factors BAF60a, b, and c in nutrient signaling and metabolic control. Protein Cell. 2018 Feb;9(2):207-15.

86 Zech M, Lam DD, Francescatto L, Schormair B, Salminen AV, Jochim A, et al. Recessive mutations in the $\alpha 3$ (VI) collagen gene COL6A3 cause early-onset isolated dystonia. Am J Hum Genet. 2015 Jun;96(6):883-93.

87 Jochim A, Li Y, Zech M, Lam D, Gross N, Koch K, et al. Microstructural white matter abnormalities in patients with COL6A3 mutations (DYT27 dystonia). Parkinsonism Relat Disord. 2018 Jan;46:74-8.

88 Demir E, Sabatelli P, Allamand V, Ferreiro A, Moghadaszadeh B, Makrelouf M, et al. Mutations in COL6A3 cause severe and mild phenotypes of Ullrich congenital muscular dystrophy. Am J Hum Genet. 2002 Jun;70(6): 1446-58.

89 Lampe AK, Dunn DM, von Niederhausern AC, Hamil C, Aoyagi A, Laval SH, et al. Automated genomic sequence analysis of the three collagen VI genes: applications to Ullrich congenital muscular dystrophy and Bethlem myopathy. J Med Genet. 2005 Feb;42(2): $108-20$.

90 Edwards TL, Michels KA, Hartmann KE, Velez Edwards DR. BET1L and TNRC6B associate with uterine fibroid risk among European Americans. Hum Genet. 2013 Aug;132 (8):943-53.

91 Kinter J, Lazzati T, Schmid D, Zeis T, Erne B, Lützelschwab R, et al. An essential role of MAG in mediating axon-myelin attachment in Charcot-Marie-Tooth 1A disease. Neurobiol Dis. 2013 Jan;49:221-31.

92 Lossos A, Elazar N, Lerer I, Schueler-Furman O, Fellig Y, Glick B, et al. Myelin-associated glycoprotein gene mutation causes PelizaeusMerzbacher disease-like disorder. Brain. 2015 Sep;138(Pt 9):2521-36.

93 Vetrugno R, Liguori R, D'Alessandro R, D’Angelo R, Alessandria M, Montagna P. Axial myoclonus in paraproteinemic polyneuropathy. Muscle Nerve. 2008 Oct;38(4):13305.

94 Rose NR. Learning from myocarditis: mimicry, chaos and black holes. F1000Prime Rep. 2014 May;6:25.
95 Whitton JL, Fujinami RS. Viruses as triggers of autoimmunity: facts and fantasies. Curr Opin Microbiol. 1999 Aug;2(4):392-7.

96 Crowe W, Allsopp PJ, Watson GE, Magee PJ, Strain JJ, Armstrong DJ, et al. Mercury as an environmental stimulus in the development of autoimmunity - A systematic review. Autoimmun Rev. 2017 Jan;16(1):72-80.

97 Vatanen T, Kostic AD, d'Hennezel E, Siljander $\mathrm{H}$, Franzosa EA, Yassour M, et al.; DIABIMMUNE Study Group. Variation in microbiome LPS immunogenicity contributes to autoimmunity in humans. Cell. 2016 May;165(4):842-53.

98 Zhou Q, Qiu H. The mechanistic impact of $\mathrm{N}$-glycosylation on stability, pharmacokinetics, and immunogenicity of therapeutic proteins. J Pharm Sci. 2019 Apr;108(4):1366-77.

99 Travers TS, Harlow L, Rosas IO, Gochuico BR, Mikuls TR, Bhattacharya SK, et al. Extensive citrullination promotes immunogenicity of HSP90 through protein unfolding and exposure of cryptic epitopes. J Immunol. 2016 Sep;197(5):1926-36.

100 Torosantucci R, Sharov VS, van Beers M, Brinks V, Schöneich C, Jiskoot W. Identification of oxidation sites and covalent crosslinks in metal catalyzed oxidized interferon Beta-1a: potential implications for protein aggregation and immunogenicity. Mol Pharm. 2013 Jun;10(6):2311-22.

101 Ansari NA, Dash D. Amadori glycated proteins: role in production of autoantibodies in diabetes mellitus and effect of inhibitors on non-enzymatic glycation. Aging Dis. 2013 Feb;4(1):50-6.

102 Perley CC, Brocato RL, Kwilas SA, Daye S, Moreau A, Nichols DK, et al. Three asymptomatic animal infection models of hemorrhagic fever with renal syndrome caused by hantaviruses. PLoS One. 2019 May; 14(5): e0216700.

103 Poland GA, Whitaker JA, Poland CM, Ovsyannikova IG, Kennedy RB. Vaccinology in the third millennium: scientific and social challenges. Curr Opin Virol. 2016 Apr;17:116-25.

104 Kanduc D. Immunogenicity, immunopathogenicity, and immunotolerance in one graph. Anticancer Agents Med Chem. 2015; 15(10):1264-8.

105 Qiao J, Zhou G, Ding Y, Zhu D, Fang H. Multiple paraneoplastic syndromes: myasthenia gravis, vitiligo, alopecia areata, and oral lichen planus associated with thymoma. J Neurol Sci. 2011 Sep;308(1-2):177-9.

106 Kanduc D. The self/nonself issue: A confrontation between proteomes. Self Nonself. 2010 Jul;1(3):255-8.

107 Ryabkova VA, Shubik YV, Erman MV, Churilov LP, Kanduc D, Shoenfeld Y. Lethal immunoglobulins: autoantibodies and sudden cardiac death. Autoimmun Rev. 2019 Apr; 18(4):415-25.

108 Kanduc D, Shoenfeld Y. From HBV to HPV: designing vaccines for extensive and intensive vaccination campaigns worldwide. Autoimmun Rev. 2016 Nov;15(11):1054-61. 